\title{
The Empirical Analysis on Spillover Effect of Construction Industry's FDI in Zhejiang
}

\author{
WANG Le \\ School of Economics \& Management \\ Taizhou University \\ Zhejiang Taizhou 318000 China
}

\author{
LI Bingqiang \\ School of Economics \& Management \\ Taizhou University \\ Zhejiang Taizhou 318000 China
}

\begin{abstract}
This article analyzed status quo of construction industry's FDI firstly, then made empirical analysis on spillover effect of construction industry's FDI in Zhejiang by using panel data model, and came conclusions that FDI in the construction industry output has strong positive spillover effect on domestic construction enterprises and the negative spillover effect on the number of domestic construction enterprises' employing. At last, this article made arrangements on elevating spillover effect of Zhejiang construction industry's FDI from aspects of promoting quality of construction industry's FDI, caring regions' balanced development, strengthening human capital's cultivation, accelerating foreign market's development.
\end{abstract}

\section{Keywords:Construction industry;FDI;Spillover effect}

CLC numbers:F832.6 Document code:A

\section{THE ISSUES RAISED}

As our country's economy has been gradually developing in depth, the ability to attract foreign capital is gradually strengthened too, performing that the FDI has been attracted since the reform and opening that presents obvious upward trend. Zhejiang is located at the coastal areas with the rapid development of economic, the growth rate of attracting FDI is higher than the overall national average, while as a traditional industry in Zhejiang, the construction industry has become the focus of foreign investment.Since 2000, Zhejiang economy has get into the overall development of the relative difficulties that the growth rate has shown a significant decline .For example in the whole country it slipped from No. 5 in 2000 to the first two national countdowns in 2012. As the construction industry has a relatively high profit margins, prompting many of the industrial enterprises in order to chase profits to choose to enter the industry, and foreign investment has also played an important role in the development of the construction industry and the real estate industry in Zhejiang, So it is necessary to analyze the construction industry's FDI spillover effects in Zhejiang

For the construction and the development of FDI in Zhejiang, Zhang Yi, Ye Bin (2009) considered that it can be divided into four stages, and discussed in terms of industry size, structure adjustment, enterprise strength, market order and so on, while Shi Xiaodong (2001) believe that after joining the WTO Zhejiang construction market canceled the market barriers and protective barriers to provide a wider space for the introduction of FDI, Liu lingling, Hu Xuan (2006) pointed out that the real estate industry has become an important industry in Zhejiang which can attract FDI. About the related research on construction FDI spillovers, scholars have taken our country date to analyze, such as LinXiaolan's (2008) construct indicators measured the squeezing effect of the China's construction FDI to the inward-funded construction industry, Wu Xianhua, Guo Ji, Zhong Nian(2007) adopted the panel data model of analys is results which indicate that there is no spillover effects of the construction industry FDI to the inward-funded construction industry in general but in different regions of view its spillover effect is more obvious, Dai Yongan, Chen Cai (2010) findings suggest that the construction industry's FDI in central region is conducive to introduce into capital for domestic enterprises and the impact on the West is opposite.

Seeing from the above studies, in our country some people has studied the spillover effects of construction industry's FDI and the development of FDI in Zhejiang Province, but studies has not yet been found for the spillover effect of construction industry's FDI in a region, which is the entry point of this article's study. Subsequently, proposing that on the basis of observing the development status about the construction industry's FDI in Zhejiang construct mathe matical models and take the panel data to study of the factors that affect spillover effects of the construction industry's FDI in Zhejiang and on this basis propose measures arrangements that will help it bring into play the spillover effects of the construction industry's FDI in Zhejiang

\section{THE ST ATUS QUO ANALYSIS OF CONSTRUCTION INDUSTRY'S FDI IN ZHEJIANG}

Analyzes of the status quo of construction industry's FDI in Zhejiang from the number of items, contractual foreign capital, actual foreign capital three aspects, About the Zhejiang 2010-2010 construction FDI related data are listed in Table 1. From the number of items to see, in 2000-2004 it increased obviously but in 2005-2009 years there has been a rapid downward trend, so it can be considered that the relative difficulty of Zhejiang economic development especially in recent years the state of the construction industry has strengthened the regulation, which is not 
conducive to the absorption of foreign direct investment. From the contractual foreign capital perspective, in 2001, it reached a maximu $\mathrm{m}$ before the decline occurs, but in 2005 it reached a relatively large figure. Take into account that the global financial crisis broke out in 2008, but in 2007 it has already a greater impact, thus resulting in the contractual foreign capital into a trough in 2007, such as contractual foreign capital was only $\$ 21,230,000$ that year. there has been a substantial improvement about the Contractual foreign capital in 2010 , which may be related with this situation that the state canceled the foreign capital into the performance evaluation area and Zhejiang economy faces major transformation and resulting in a large number of foreign capital from the industry to the real estate industry and the construction industry. Due to the economic situation at home and abroad and large-scale construction projects often take a phased arrive impact, resulting in greater volatility in the actual foreign capital, such as the maximum and minimum values between 2000-2010 were $\$ 107,250,000$ and $\$ 12,380,000$, and the minimu $m$ value in 2008 was related with that the financial crisis led to the relative difficulty of financing foreign enterprises.
Now turn to the investigation and analysis of the proportion of Zhejiang construction industry's FDI in the country. From looking at the proportion of the whole country, the proportion of the number of projects between 2000 and 2005 were more than $5 \%$, then tax dropped fairly obvious, such as the proportion from 2007 to 2010 were both below $3 \%$. From the proportion of contractual foreign capital to see, except in 2007 and 2009, the proportion of the whole country was more than $5 \%$, showing that compared with the whole country Zhejiang individual projects with large amount of investment. Among them, in 2007 accounting for only $1.27 \%$ shows that the construction in Zhejiang suffered a greater impact of the global financial crisis, and it can be seen from Zhejiang actual investment amount that accounted for only $1.13 \%$ of the whole country in the 2008. However, in 2010, Zhejiang Construction contracted foreign investment of up to $15.50 \%$ of the country, which may be related to this situation that Zhejiang folk financial capital chain was broken that led to foreign Industrial shift from large capital construction and real estate. Looking at the proportion from the actual investment amount, except 2002, 2004, 2008 years, the value was greater than the proportion of the number of investment projects in the country in other years.

Table $12000-2010$ the proportion of foreign direct investment in the construction industry in the whole country

\begin{tabular}{|c|c|c|c|c|c|c|}
\hline \multirow{2}{*}{ Years } & \multicolumn{2}{|l|}{ Project } & \multicolumn{2}{c|}{ Contractual foreign capital } & \multicolumn{2}{c|}{$\begin{array}{c}\text { The actual investment } \\
\text { amount }\end{array}$} \\
\cline { 2 - 7 } & $\begin{array}{l}\text { Quantity } \\
\text { (A) }\end{array}$ & $\begin{array}{c}\text { Proport } \\
\text { ion (\%) }\end{array}$ & $\begin{array}{c}\text { Sum } \\
\text { (U.S.\$ million) }\end{array}$ & $\begin{array}{c}\text { Proport } \\
\text { ion (\%) }\end{array}$ & $\begin{array}{c}\text { Sum } \\
\text { (U.S. } \\
\text { \$ million) }\end{array}$ & $\begin{array}{c}\text { Proport } \\
\text { ion (\%) }\end{array}$ \\
\hline 2000 & 13 & 5.58 & 9530 & 11.47 & 7544 & 8.33 \\
\hline 2001 & 14 & 5.47 & 24899 & 13.66 & 10725 & 13.29 \\
\hline 2002 & 18 & 5.47 & 13070 & 12.36 & 3574 & 5.04 \\
\hline 2003 & 24 & 6.06 & 11882 & 7.08 & 4683 & 7.65 \\
\hline 2004 & 25 & 6.08 & 9296 & 5.26 & 4290 & 5.56 \\
\hline 2005 & 23 & 5.03 & 20667 & 8.05 & 4415 & 9.01 \\
\hline 2006 & 11 & 3.13 & 19898 & 9.27 & 7477 & 10.87 \\
\hline 2007 & 8 & 2.60 & 2123 & 1.27 & 2814 & 6.48 \\
\hline 2008 & 5 & 1.91 & 7022 & 6.64 & 1238 & 1.13 \\
\hline 2009 & 4 & 1.82 & 8958 & 4.91 & 8826 & 12.76 \\
\hline 2010 & 8 & 2.90 & 12878 & 15.50 & 6982 & 4.78 \\
\hline
\end{tabular}

Source: over the years "Zhejiang Statistical Yearbook", "China Statistical Yearbook".

III. THE MATHEMATICAL MODEL AND THE EMPIRICAL ANALYSIS OF THE SPILLOVER EFFECT S OF CONST RUCTION INDUSTRY'S FDI IN ZHEJING

\section{A. Model building}

Generally believed that the effect of FDI on the construction industry spillovers mainly perform in the innerowned construction enterprise output, the amount of laborfunded construction enterprises, foreign construction companies outputs three areas. The basic model of the spillover effect is set to:

$$
F D I=A \cdot Y^{\alpha} \cdot L^{\beta} \cdot Y_{f}^{\gamma}
$$

(1)

Which, FDI, Y, L, and Yf denote construction FDI, the total output of domestic construction enterprises, the number of labor-funded construction enterprises, foreign construction companies in total output. $\alpha, \beta, \gamma$ and size of the sign reflects the direction and intensity of the spillover effects of foreign investment.

Formula (1) on both sides of logarithmic, we get:

$$
\ln F D I=\ln A+\alpha \ln Y+\beta \ln L+\gamma \ln Y_{f}+\varepsilon
$$

Where, $\varepsilon$ is a disturbance. 
The $\ln \mathrm{A}$ expressed by c, we get:

$$
\ln F D I=c+\alpha \ln Y+\beta \ln L+\gamma \ln Y_{f}+\varepsilon
$$

(3)

(3) is the measure of the spillover effects of FDI on the basic model, in Zhejiang Province.

\section{B. An Empirical Analysis}

This article takes the data that is related to panel data of five regions from 2006 to 2010 in Zhejiang Province, Hangzhou, Ningbo, Jiaxing, Huzhou, Taizhou, data from the Statistical Yearbook of various regions over the years. Since Taizhou has no construction industry FDI data in 2006-2008 years, in order to maintain data consistency so it uses the real estate data instead. In addition, in "Jiaxing City Statistical Yearbook", In 2009 the construction of FDI data in contractual foreign investment and actual investment data is not complete, so using the related proportion of the construction industry's FDI to total FDI to compare and analyze, and estimate its value. the total FDI by the construction industry, the proportion of FDI-related comparative analysis, and then estimate its value.

Considering the less data of the Zhejiang construction industry's FDI, therefore take the mixed estimation of panel data model to study. Before the empirical analysis, the first is to describe the relevant indicators that were taken: FDI is the actual amount of foreign investment in units of ten thousand dollars; domestic and foreign construction enterprises output value in units of ten thousand Yuan; domestic construction enterprises of the number of labor force in units of ten thousand people

It is necessary to make a statement, because the number of foreign-funded enterprises in the construction industry in Jiaxing 2008-2010 is 0 , resulting output is also 0 , but in order to logarith mic of need, the foreign construction output is set to 10,000 Yuan, which should not have a greater impact on the outcome of output. Putting the relevant data into a given measurement model, the construction industry has been characterized Zhejiang FDI spillovers empirical results, shown in Table 2.

Table 2 The results of econometric analysis

\begin{tabular}{|l|l|l|l|}
\hline & Model 1 & Model 1 & Model 3 \\
\hline $\mathrm{c}$ & -8.530 & 7.663 & -6.852 \\
\hline$\alpha$ & $1.294(2.473)$ & $-0.102(0.626)$ & $1.147(2.109)$ \\
\hline$\beta$ & & $0.052(1.346)$ & $0.038(0.980)$ \\
\hline$\gamma$ & $-1.494(2.588)$ & & $-1.405(2.403)$ \\
\hline DW value & 1.833 & 1.755 & 1.896 \\
\hline P value & 0.038 & 0.406 & 0.059 \\
\hline
\end{tabular}

Note: Figures in parentheses are t values

Generally believed that the construction FDI will first affect domestic construction companies, thus it will have an impact on the number of domestic building practitioners, and it will also drive the output of foreign construction enterprises. Theoretically, foreign construction companies should be positively correlated with the output of the construction industry FDI, but due to the influence of various factors, it may have the uncertain impact on the internal output and the number of domestic construction enterprise employees. From the above three models to see, model 2 because the $\mathrm{P}$ value is too high and the output of the variable-owned construction companies did not pass the test of significance, it can be considered that it is not suitable for analys is. Both model 1 and model 3 of each variable (except for foreign construction enterprises output indicators) have passed the test of significance, and $\mathrm{P}$ values of the two models are less than 0.1 , so that this index is not suitable for the analysis of foreign construction enterprises output. According to the above analysis, it can be inferred that model 1 is the most reasonable model, which can be used to analyze the economic implications of its characterization

The model 1 shows, elastic FDI to domestic construction enterprise output and domestic building enterprises employed numbers are 1.293 and -1.494 respectively, the domestic construction enterprise output has positive externalities stronger, and negative spillover of domestic construction enterprises professional number is also more obvious. Output of domestic-funded construction enterprises with a positive spillover of foreign direct investment is mainly possible through cooperation with local construction companies and thus enhances productivity, while negative spillover to the number of employees may be closely related with that the foreign lead to dominance of talent loss

\section{A SPILLOVER EFFECT OF FDI MEASURES TO ACCELERATE THE CONST RUCTION OF ZHEJIANG}

Effective play in the construction industry FDI spillover effects which are closely related to the government's macrocontrol and management, while the subjective initiative of 
enterprises is also important to consider level, and therefore intend to enhance the construction industry from FDI quality, focus on balanced regional development, strengthen human capital training, speed overseas market development and other aspects of how to improve measures of Zhejiang construction FDI spillover effects.

Improve the quality of construction FDI. Zhejiang gradually opening the market will inevitably make a lot of the foreign construction enterprises get into, such as the construction industry in Zhejiang Province in 2011 reached 32. Rapid economic development in Zhejiang and improve living standards for the construction of a higher quality requirements, thereby enhancing the quality of FDI to stimulate the local construction companies and thus enhance the quality of construction and architectural design has become an important path. For example, by actively introducing foreign famous architectural designers and developers to form groups of various styles of architecture, and thus will fight livable Zhejiang, ecological, featuring living environment.

Pay attention to the balanced regional development. Development of regional presence of foreign direct investment in the construction industry in Zhejiang exists large regional differences, such as the Hangzhou, Ningbo, Shaoxing and other regional gather momentum obvious, Jiaxing, Huzhou, Taizhou and other regions attracting the number of FDI is relatively less, that developed regions can introduce more FDI but underdeveloped regions attract more less. Therefore, all levels of government in Zhejiang, have a guide to guide the construction industry to actively attract FDI in developed regions, while the introduction of land tax and other incentives should be taken to promote the construction industry in underdeveloped regions of the introduction of FDI, which can improve the spillover effects of the construction industry's to the local Zhejiang construction enterprises, driven by a relatively balanced development in all regions to promote collaboration

Strengthen human capital training. The empirical analys is results, the negative spillover of FDI to inward-owned construction companies employed is more obvious, which is directly related to the treatment of the rich in foreign construction companies and the development of better prospects, thereby resulting in a brain drain of local construction companies are obvious. Therefore, local construction companies should be strengthened emphasis on human capital, such as the adoption of domestic training, overseas training, colleges and universities to provide docking and other measures for employees, employees in improving the quality of the building, while strengthening the competitiveness of enterprises. Such as collaborate with top foreign construction companies, regularly or irregularly send employees out exchanges.

Accelerate the development of overseas markets. In the construction industry continues to attract foreign investors into the Zhejiang market, domestic enterprises should gradually into overseas markets. Therefore, Zhejiang should not only actively introduce manufacturing foreign direct investment, should also stimulate local construction enterprises to gradually implement the "going out" policy, vigorously develop foreign direct investment. Domestic construction companies go to developed countries with a higher level of building development, which is more conducive to domestic and foreign companies negotiating and building design and development issues, Through imitation and demonstration effects of absorbing and using the advanced construction technology, at the same time in the development of service industry in the host country the construction industry, it is used to improve the human capital and the capital stock of Zhejiang construction enterprises, and make construction enterprises realize great leap forward development of Zhejiang to the extension of a higher level.

\section{REFERENCES}

[1] Dai Yongan, Chen Cai. Empirical analysis on the influence mechanism of FDI on domestic building enterprise [J]. Economics and management, 2010 (3): 44-48.

[2] Lin Xiaolan. Squeezing effect of FDI on capital formation in China's construction industry analysis [J]. Jiangsu provider's theory, 2008 (7): $152-154$.

[3] Lingling, Hu Xuan An Empirical Study of FDI and industrial structure in Zhejiang Province [J]. Enterprise technology development, 2006 (8): 9496.

[4] Shi Xiaodong impact of WTO accession on the construction industry in Zhejiang [J] .Building, 2001 (12): 16-19.

[5] Wu Xianhua, Bell read my domestic-funded enterprises FDI spillover effects panel data analysis: In the construction industry as an example $[\mathrm{J}]$.Contemporary Finance, 2007 (1): 95-99.

[6] Zhang Yi, Ye Bin historical witness brilliant - Zhejiang Construction 30 Years of Reform and Opening [J] building, 2009(1): 24-27. 